The last of four elements of the Mental Health Project, established by the College of Occupational Therapists to produce a position paper on the way ahead for research, education and practice in occupational therapy in mental health (Craik et al 1998a), focused on educating occupational therapy students to work in mental health.

First, the views of practitioners about their pre-registration education were derived from one component of the practitioners' survey (Craik et al 1998b). One hundred and eleven $(\mathbf{8 1} \%)$ practitioners considered that their preregistration education had been sufficient or partially sufficient to meet their needs on first working in mental health.

Secondly, the views of occupational therapy educators were elicited by a short qualitative survey that replicated three questions about future issues in mental health, which had formed a key constituent of both the practitioners' survey (Craik et al 1998b) and the managers' survey (Craik et al 1999). Important issues for educators were focusing on clients who would benefit most from occupational therapy in community and primary care settings, preparing undergraduates for the unique approach of occupational therapy and the need for more research to support evidence-based practice. Both groups highlighted the value of positive fieldwork placements.

\title{
Educating Occupational Therapists for Mental Health Practice
}

\author{
Christine Craik and Chris Austin
}

\section{Introduction}

This is the last of four elements of the Mental Health Project, established by the College of Occupational Therapists to produce a position paper on the way ahead for research, education and practice in occupational therapy in mental health. The key findings of each of the four elements of the project, including this one, were synthesised to produce the position paper (Craik et al 1998a). The project began with a review of the literature on occupational therapy in mental health (Craik 1998), surveyed practitioners who worked in mental health (Craik et al 1998b) and surveyed managers in mental health (Craik et al 1999). This final element related to educating occupational therapists to work in mental health and incorporated the views both of practitioners in mental health and of occupational therapy educators.

In general, the review of the literature on occupational therapy in mental health (Craik 1998), which served as a basis for all aspects of the Mental Health Project, exposed a paucity of studies on the subject. It established that there was little literature that focused on the education of occupational therapists for practice in mental health and much of what had been published related to the profession in the USA. Here the predominant theme was the diminishing number of therapists choosing to practise in mental health and the efforts to redress the situation, with several studies focusing on the views of students.
In a seminal paper, Barris and Kielhofner (1986) surveyed 34 of the 53 occupational therapy schools in the USA, with educators identifying that the key problems in mental health were the lack of a clear role definition, of a unifying theory and of research validating the profession. In a similar vein, Bartlow and Hartwig (1989) surveyed 136 occupational therapy practitioners in mental health in Australia about assessment, practice and frames of reference in mental health and concluded that there was no consensus about scope of practice, assessments or service delivery.

In the USA, several studies considered the student perspective. Ezersky et al (1989), in a survey of 411 occupational therapy graduates, established that therapists chose their area of specialty due to their fieldwork experience, their feelings of efficacy in the area and the availability of employment. In the same year Whittman et al (1989) discovered that, prior to commencing their occupational therapy studies, $13 \%$ of the 212 students surveyed preferred mental health and this decreased to $12 \%$ at the time of job selection. However, these students noted that the most negative part of their education was a preclinical fieldwork placement. In contrast, more than half of the 152 practitioners in Atwater and Davis' (1990) survey about mental health fieldwork placements indicated that the placements had influenced their career choice and, of these, about half reported a positive influence. Lyons (1995), in a small qualitative study of 16 occupational therapy students 
from the USA and Australia, concluded that fieldwork placements in community mental health settings were necessary if future therapists were to be prepared for practice in these settings.

By 1996, Paul (p65) considered mental health 'an endangered occupational therapy specialty' in the USA and emphasised good fieldwork placements, the personal commitment of practitioners and the American Occupational Therapy Association making mental health a priority as strategies to redress the situation. Philipps et al (1997) examined the preadmission factors influencing the practice area preference of 219 applicants to the undergraduate occupational therapy programme in Virginia Commonwealth University. They found that only 11\% expressed a preference for working in mental health, which compares with the 13\% noted by Whittman et al (1989). Among their recommendations, Philipps et al (1997) urged university recruiters to seek out students with positive views on mental health and mental health clinicians to provide positive fieldwork experiences for students.

In the UK, no similar studies were found. However, Atkinson and Steward (1997) followed up the first cohort of occupational therapy students from the University of East Anglia and, although the study did not focus on preparation for mental health practice, it did reveal some relevant findings, with 10 of their sample of 24 graduates working in mental health. The graduates identified, both prior to leaving university and post-qualification, the areas where they felt adequately and inadequately prepared for practice. Post-qualification, the graduates felt inadequately prepared in areas that were more peripheral to occupational therapy, in specific rather than general assessments and in atypical interventions. They recognised that 'their level of ability had changed through increasing confidence' (Atkinson and Steward 1997, p341). The value of fieldwork placements was noted, especially where the placement had been in the area in which they now worked.

\section{Aims}

This element of the project was in two parts. The first part aimed to ascertain the opinions of practitioners about their pre-registration education in preparation for their role as occupational therapists in mental health. The second part explored the opinions of occupational therapy educators about occupational therapy in mental health. The findings from both parts were then compared and discussed. The aim was to give an overview of opinion on education in mental health.

\section{Method}

Two differing methodologies were employed, one for each aspect of this study. First, the views of practitioners about their pre-registration education were derived from one component of the questionnaire sent to 200 members of the
Association of Occupational Therapists in Mental Health (AOTMH); full details are reported in Craik et al (1998b). The results of this component, like those of the larger study, were analysed using the Statistical Package for Social Sciences (SPSS) and content analysis.

Secondly, the views of educators were elicited by a short qualitative questionnaire. This replicated three questions about future issues in mental health, which formed a key constituent of both the practitioners' survey (Craik et al 1998b) and the managers' survey (Craik et al 1999). The questionnaire was sent to the 30 directors of undergraduate occupational therapy education courses in the UK. These results, like those in the previous two studies, were analysed by content analysis.

\section{Results}

As this study is part of a series, the results are presented in a broadly similar way to those in the previous two studies to facilitate comparison.

\section{Practitioners}

Of the 200 questionnaires sent to practitioners, 137 were returned representing a 68.5\% response rate. All 137 practitioners responded to a fixed choice question and gave their opinion on whether their pre-registration education had been sufficient, partially sufficient or not sufficient to meet their needs when they commenced working in mental health. Fifty-one (37\%) practitioners considered that it had been sufficient, 60 (44\%) considered that it had been partly sufficient and the remaining 26 (19\%) judged it insufficient. These results were then examined in relation to the variables of the age of the practitioners, the time that they had worked in mental health and their grade. No statistical significance was established, but a pattern emerged with the latter two variables.

\section{Time worked in mental health}

Looking first at the sufficiency of pre-registration education in relation to the time worked in mental health, the original data were collected in five time bands. These time bands produced categories of differing sizes so, to facilitate comparison, they were collapsed into three time bands of more balanced size. The 53 therapists who had worked for less than 5 years formed one category and the 44 therapists who had worked for more than 11 years created another category, leaving the remaining 40 therapists who had worked for between 6 and 10 years as the third category. To facilitate comparison further, the results are displayed in Fig. 1 as percentages within each category.

The practitioners who had worked in mental health for less than 5 years and those who had worked for more than 11 years displayed a similar pattern, with the majority considering that their pre-registration education had been partly sufficient. In contrast, the largest group of practitioners who thought that their pre-registration education had been sufficient had worked for between 6 and 


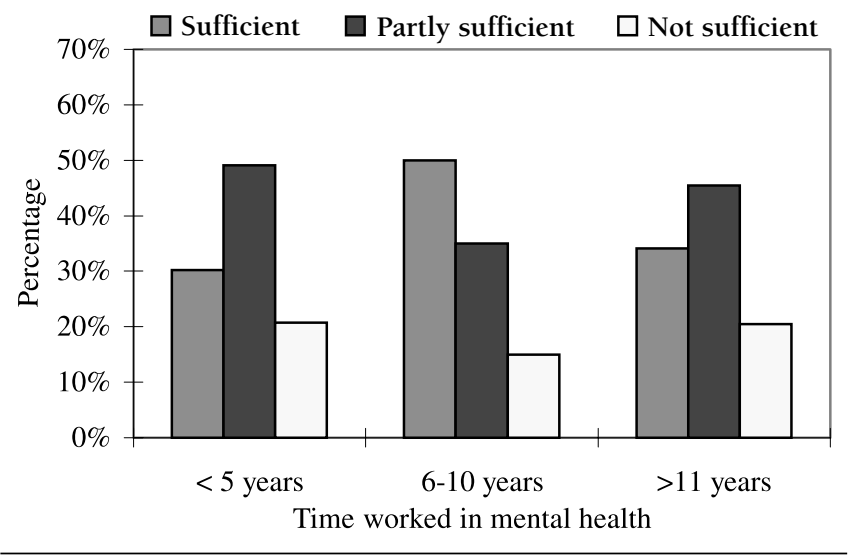

10 years. These results are shown in Fig. 1 according to length of time worked in mental health.

\section{Grade}

When considering the sufficiency of pre-registration education by grade of therapist, the original data were collected according to eight grades creating categories of differing sizes. These were collapsed into four more equal categories by placing all head occupational therapists and those noted as 'other' into one group of 41 staff. The three other categories remained the same with 15 basic grade therapists, 22 senior II therapists and 59 senior I therapists. The results are shown in Fig. 2, as percentages within each category. The patterns were broadly similar for three of the groups but the senior II therapists showed a different pattern, with the majority considering that their preregistration education had been partly sufficient.

Fig. 2. Sufficiency of pre-registration education of 137 practitioners in relation to their grade.

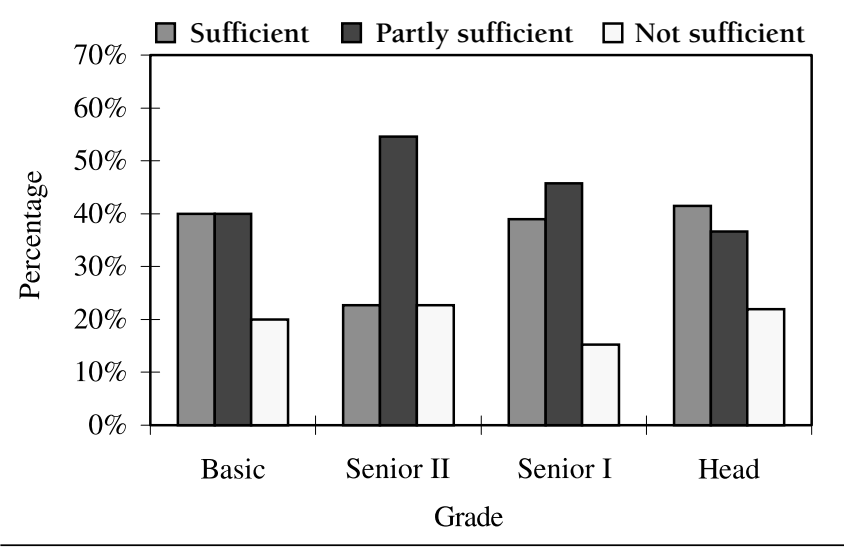

\section{Additional comments}

Invited to provide additional comments about their preregistration education, 101 (74\%) practitioners did so. Examining these comments in relation to the practitioners' view of their education was interesting. Of the 51 practitioners who considered that their education had been sufficient, 26 (51\%) supplied additional comments; however, over $80 \%$ in the other two categories did so, creating more potentially negative comments.
Considering the variety of educational establishments that the respondents had attended and the varied length of time since graduating, it is difficult to draw conclusions from the comments. In general, those who judged their preregistration education as sufficient considered that the basic information had been included. A head occupational therapist commented, 'I felt well grounded in mental health occupational therapy practice', while a basic grade noted, 'I believe I had a firm foundation on which I could continue to develop knowledge and skills'. Other therapists also acknowledged the importance of their previous experience, post-qualification supervision and further training. A senior I occupational therapist observed: 'I needed supervision to develop skills and knowledge.'

Those who regarded their pre-registration education as not sufficient highlighted that it was too theoretical and not practical enough, with too few fieldwork placements. Some respondents noted the aspects that they considered lacking. A senior I occupational therapist reported 'a lack of training in risk assessment, psychotic phenomena and ethical implication of mental health practice'. Difficulties were noted where the first post was in a specialist area or when supervision was inadequate. Five respondents noted the comparison with education for physical disabilities: 'Undergraduate courses tended to focus more on role of occupational therapy with clients with physical dysfunction. Although some mental health was covered, it was not in the same depth or with the same enthusiasm from lecturers.'

Similar comments were made by five respondents who deemed that their pre-registration education was partly sufficient. They also commented on the lack of training in specific assessments and techniques and the subsequent problems of coping with the realities of practice. Of particular interest were the seven therapists who commented that their pre-registration education had been insufficient or partly sufficient, but that their fieldwork placements in mental health had been a valuable learning experience.

In summary, 111 (81\%) practitioners considered that their pre-registration education had been sufficient or partially sufficient to meet their needs when they first began practising in mental health.

\section{Educators}

Of the questionnaires sent to the 30 directors of undergraduate occupational therapy education courses in the UK, 21 were returned representing a 70\% response rate. The questionnaires had been completed by the director, sometimes in conjunction with colleagues, or by an educator with responsibility for mental health. They responded to the open question: 'Thinking of the future, what do you think are the three most important issues facing occupational therapists working in mental health?' All respondents identified three issues with some containing more than one topic, creating a total of 75 issues. The results were analysed in a similar way to those in the previous two studies. They were examined for similarities and clustered and, because there was little variation in the pattern between the first, second and third responses, they were considered together. 
The largest cluster focused on community services and the need for occupational therapists 'to become much more involved within community primary care environments in their broadest contexts - GP services, homelessness teams, voluntary sector initiatives'. Occupational therapists 'need to influence policies on how mental health services are structured and delivered'. This should be accomplished through local management, marketing and promotion and national campaigning. Linked to this was clarity of priorities in determining which client groups would benefit most from occupational therapy.

Secondly, the importance was emphasised of 'being certain of the unique approach of the occupational therapist in this field and teaching it to students so they have the confidence to be real occupational therapists and not be side-tracked by skills of other disciplines'. This was especially relevant because of 'the increasing role of talking therapies, that is, cognitive and solution focused brief therapy and the loss of traditional activities such creative therapies'.

The third cluster supported the requirement for a stronger research base to support evidence-based practice and included the need for clinical practice to be more explicit and 'for more to be published in multiprofessional journals demonstrating efficacy of occupation as therapy'.

The fourth cluster concerned service changes that have left many individual clinicians isolated and unsupported, which was perceived to have affected recruitment and retention adversely. Also recognised was the need for 'support and supervision - for both personal and professional reasons'.

The fifth cluster emphasised the centrality of occupation to occupational therapy and highlighted 'making the most of therapeutic activity to bring about real change in the client'. As in the previous two studies, the number and percentage of responses in each cluster is shown in Table 1.

\section{Table 1. Summary of the three most important issues facing occupational therapists working in mental health provided by occupational therapy educators}

\begin{tabular}{|c|c|c|}
\hline Cluster & Number & $\%$ \\
\hline \multicolumn{3}{|l|}{ Focus on community and primary care and on clients } \\
\hline \multicolumn{3}{|l|}{ who will benefit most, more influence on policies, more } \\
\hline \multicolumn{3}{|c|}{ occupational therapy managers, promotion and marketing. $20 \ldots .27$} \\
\hline \multicolumn{3}{|l|}{ Define specific skills and role of occupational therapy as } \\
\hline \multicolumn{3}{|c|}{ distinct from other professions and prepare undergraduates } \\
\hline for the unique approach of occupational therapy & 17. & .23 \\
\hline \multicolumn{3}{|l|}{ Need for more research to be undertaken and published, } \\
\hline \multicolumn{3}{|l|}{ including developing outcome measures, to support } \\
\hline \multicolumn{3}{|c|}{ evidence-based practice $\ldots \ldots \ldots \ldots \ldots \ldots \ldots \ldots 14 \ldots \ldots 18$} \\
\hline \multirow{2}{*}{\multicolumn{3}{|c|}{$\begin{array}{l}\text { More working in multidisciplinary teams requires stronger } \\
\text { professional identity, support and supervision and more }\end{array}$}} \\
\hline & ore & \\
\hline effective recruitment and retention & 9. & .12 \\
\hline \multicolumn{3}{|l|}{ Focus on activity and occupation and shift to leisure and } \\
\hline social activity & & .11 \\
\hline Funded continuing professional development & 3. & \\
\hline Miscellaneous. & & \\
\hline Total. & .75. & \\
\hline
\end{tabular}

Fifteen of the 21 educators provided additional comments. In general, they embellished the themes already identified; however, several new points were made. A lack of resources limited the scope of occupational therapy, but the potential of the profession in health promotion was highlighted. The move to work in community mental health teams had restricted the availability of student placements and the drift towards generic working had created 'fewer good occupational therapy role models for students'.

\section{Discussion}

It was encouraging to note that $81 \%$ of the 137 practitioners considered that their pre-registration education had been sufficient or partially sufficient when they first began working in mental health, with the largest group who regarded it as sufficient having worked between 6 and 10 years. Those who judged it not sufficient for their needs identified that the more specialist areas of practice were lacking, supporting the views of the graduates in Atkinson and Steward's (1997) study. The question may not have been sensitive enough to distinguish between pre-registration education and subsequent supervision and training, again echoing the findings of Atkinson and Steward (1997) whose graduates recognised the role of experience in enhancing their feelings of confidence. Paradoxically, as these therapists developed their knowledge and skills in mental health through experience, supervision and further training, their views of any shortcomings of their pre-registration education may have been emphasised. The opinions of these practitioners cannot easily be generalised to other occupational therapists. Indeed, it could be argued that the respondents in this study who have chosen to work in mental health and are members of the Association of Occupational Therapists in Mental Health may, in looking retrospectively, have had over-ambitious expectations of their pre-registration education.

Of particular interest were those seven therapists who appeared to consider that fieldwork placements were a separate part of their education. The College of Occupational Therapists' (1998) curriculum framework continues to articulate the centrality of fieldwork in occupational therapy education. It is discouraging if these practitioners do not see fieldwork education in that light, especially so for any students that they may subsequently have supervised.

The educators noted the lack of fieldwork placements and good role models for students and highlighted the value of practitioners being certain of the unique approach of occupational therapy. This emphasis on fieldwork placements supports the opinions of Ezersky et al (1989), Atwater and Davis (1990), Lyons (1995), Paul (1996), Philipps et al (1997) and, especially, Atkinson and Steward (1997) whose graduates particularly valued fieldwork placements when they had been in the area in which they now practised. Indeed, one of the reasons for establishing the Mental Health Project was concern about the less than 
positive views some students expressed in relation to their mental health fieldwork placements. If students do not have positive mental health fieldwork experiences, this has the potential to create future problems with recruitment and retention leading to an uncertain future for occupational therapy in mental health. Ironically, it may be these difficulties of recruitment and retention that cause fieldwork educators to be reticent in offering placements, thus contributing to the vicious circle.

The educators, like their colleagues in the Barris and Kielhofner (1986) study, still recognised the need for more research in occupational therapy in mental health and the increasing significance placed on evidence-based practice. If these aspects can be emphasised in undergraduate education programmes, along with specific assessments and techniques, it may counter the criticism of those practitioners who felt that mental health was neglected in favour of occupational therapy for physical dysfunction. However, the educators must not disregard practical application at the expense of too much theory.

Specific areas for further research emanating from this study would include evaluating the effectiveness of mental health education in the undergraduate curriculum and exploring incentives to encourage practitioners in mental health to offer high quality fieldwork placement experiences for occupational therapy students.

Of particular interest were the similarities of the opinions expressed by these educators, the practitioners (Craik et al 1998a) and the managers (Craik et al 1999). While the emphasis between the groups may differ, the same themes predominated. If these groups of occupational therapists can establish common causes to work towards, this augurs well for the future of occupational therapy in mental health. It may be that educators can assist practitioners with occupational therapy specific continuing professional development, which may lead to the creation of the evidence-based culture that is so desired. This may, in turn, lead to more confident practitioners, willing and able to guide future generations of students on placement.

As one of the educators poignantly suggested, 'getting back to the philosophy of activity and applying this to the needs of people with mental health problems in the community' was the important issue facing occupational therapists working in mental health.

It is to be hoped that this study and other aspects of the Mental Health Project can stimulate debate and action in the profession to enable this to happen.

\section{References}

Atkinson K, Steward B (1997) A longitudinal study of occupational therapy new practitioners in their first years of professional practice: preliminary findings. British Journal of Occupational Therapy, 60(8), 338-42.

Atwater AW, Davis CG ( 1990) The value of psychosocial level II fieldwork. American Journal of Occupational Therapy, 44(9), 792-95.

Barris R, Kielhofner G (1986) Beliefs, perspectives and activities of psychosocial occupational therapy educators. American Journal of Occupational Therapy, 40(8), 535-41.

Bartlow P, Hartwig C (1989) Status of practice in mental health: assessment of frames of reference. Australian Occupational Therapy Journal, 36(4), 180-92.

College of Occupational Therapists (1998) Curriculum framework document for occupational therapy education. London: COT.

Craik C (1998) Occupational therapy in mental health: a review of the literature. British Journal of Occupational Therapy, 61(5), 186-92.

Craik C, Austin C, Chacksfield JD, Richards G, Schell D (1998a) College of Occupational Therapists: Position paper on the way ahead for research, education and practice in mental health. British Journal of Occupational Therapy, 61(9), 390-92.

Craik C, Chacksfield JD, Richards G (1998b) A survey of occupational therapy practitioners in mental health. British Journal of Occupational Therapy, 61(5), 227-34.

Craik C, Austin C, Schell D (1999) A national survey of occupational therapy managers in mental health. British Journal of Occupational Therapy, 62(5), 220-28.

Ezersky S, Havazelet L, Hiller-Scott A, Zetler CL (1989) Specialty choice in occupational therapy. American Journal of Occupational Therapy, 43(4), 227-33.

Lyons M (1995) Learning in context: perceived benefits of fieldwork education in community mental health settings. British Journal of Occupational Therapy, 58(6), 245-49.

Paul S (1996) Mental health: an endangered occupational therapy specialty. American Journal of Occupational Therapy, 50(1), 65-68.

Philipps MA, Maloney NL, Stevens AC, Madigan MJ, Cash SH (1997) Preadmission factors influencing practice area preference in occupational therapy. Occupational Therapy in Mental Health, 13(3), 23-41.

Whittman PP, Swinehart S, Cahill R, St Michael G (1989) Variables affecting specialty choice in occupational therapy. American Journal of Occupational Therapy, 43(9), 602-606.

\section{Authors}

Christine Craik, MPhil, DMS, DipCOT, MIMgt, SROT, Director of Undergraduate Occupational Therapy Studies, Brunel University, Osterley Campus, Borough Road, Isleworth, Middlesex TW7 5DU.

Chris Austin, DipCOT, BA, SROT, formerly Senior Occupational Therapist, Exeter and District Community Health Services NHS Trust. 